\title{
Erratum to: Eye-hand coordination in a sequential target contact task
}

Miles C. Bowman • Roland S. Johansson •

John Randall Flanagan

Published online: 28 December 2010

(C) Springer-Verlag 2010

Erratum to: Exp Brain Res (2009) 195:273-283

DOI 10.1007/s00221-009-1781-x

In the original publication of this article, Professor Johansson's name was wrongly spelled as 'Johannson'. It is now corrected here.

The online version of the original article can be found under doi:10.1007/s00221-009-1781-x.

M. C. Bowman · J. R. Flanagan $(\bowtie)$

Centre for Neuroscience Studies and Department of Psychology,

Queen's University, Kingston, ON K7L 3N6, Canada

e-mail: flanagan@queensu.ca

R. S. Johansson

Section for Physiology, Department of Integrative,

Medical Biology, Umeå University, 90187 Umeå, Sweden 